\title{
Immunohistochemical Expression of Cyclin D1 in Invasive Ductal Carcinoma of Human Breast
}

\author{
Mahmoud Assem ${ }^{1}$, Eman Ahmed Youssef ${ }^{1}$, Radwa Mohammed Rashad ${ }^{2}$ and Mona Abdel-Hamed Yahia ${ }^{1}$ \\ 1. Department of Histochemistry and Cell Biology, Medical Research Institute, Alexandria University, Alexandria, Egypt; \\ 2. Department of Pathology, Medical Research Institute, Alexandria University, Alexandria, Egypt.
}

$\square$ Corresponding author: Mahmoud Assem MSc, Department of Histochemistry and Cell Biology, Medical Research Institute, Alexandria University, Alexandria, Egypt. E-mail: M.Assem@alexu.edu.eg Or MahmoudAssemMohammed@gmail.com; Phone: +20-01025589478.

() Ivyspring International Publisher. This is an open access article distributed under the terms of the Creative Commons Attribution (CC BY-NC) license (https://creativecommons.org/licenses/by-nc/4.0/). See http://ivyspring.com/terms for full terms and conditions.

Received: 2016.11.19; Accepted: 2017.01.13; Published: 2017.04.06

\begin{abstract}
Cyclin DI has been observed in many human tumors and is likely to promote cell proliferation and differentiation by shortening the GI/S transition. This work was aimed to evaluate the prognostic role of Cyclin DI in invasive ductal carcinoma (IDC) and its correlation with other established prognostic parameters of breast cancer. This study was conducted on 40 prospective biopsies taken from patients with breast tumor; 30 cases having IDC and 10 cases with benign tumor as well as 10 normal biopsies. Sections from all cases were subjected to stain with haematoxylin and eosin (H\&E) for histopathological examination and immunohistochemical technique for Cyclin DI in addition using flow cytometric technique to perform cell cycle analysis. Histopathological results showed fibroadenoma and fibrocystic disease in benign cases and IDC with $60 \%$ grade II and $40 \%$ grade III in malignant cases. Immunohistochemical results revealed higher expression of Cyclin DI in IDC comparing to normal and benign breast tissues. Statistically there was significant correlation between Cyclin DI scores and the positivity of estrogen receptor (ER) and progesterone receptor (PR), and no significant correlation was seen between Cyclin DI and S-phase \%. It could be suggested that Cyclin DI protein may be a valuable prognostic marker in IDC and can be targeted in the future therapeutic approaches.
\end{abstract}

Key words: Cyclin D1, Breast cancer, Immunohistochemistry, Histopathology, Flow cytometry, IOD.

\section{Introduction}

Breast cancer representing a quarter of all cancers diagnosed in women in the vast majority of countries worldwide [1]. In US, there was an expectation that about 231,840 new cases of invasive breast cancer and 40,290 deaths among women would in 2015 [2]. The Alexandria hospital based cancer registry from 2010 to 2015 has noted that female breast cancer was $48.5 \%$ [3].

Cyclin D1 is synthesized by the transcription of the gene (CCND1) located on chromosome 11q13; it plays a critical role in the regulation of the cell cycle.
Cell cycle is controlled by a set of protein complexes consists of cyclins and cyclin dependant kinases (CDKs) together provide the cell an orderly progression throughout the cycle [4]. Cyclins have five major classes (cyclin A, B, C, D1-3 and E) [5] and CDKs family composed mainly of CDK 1, 2, 4 and 6; each phase of cell cycle has specific types of cyclin/CDK complexes which responsible for proper regulation of this phase [6].

Cyclin D1 is synthesized upon the quiescent cell receive appropriate growth stimulatory signals and 
reach their peak in early G1 phase, and then it binds to CDK4/6 activating them. This active complex phosphorylates $\mathrm{pRb}$ leading to free the transcription factor E2F from $\mathrm{pRb}$. Activated E2F leading to transcription of several target genes including cyclin $\mathrm{E}$ in late G1 phase which form active complex with CDK2 drives progression from G1 to $S$ phase [7].

Cyclin D1-levels varying throughout cell cycle, hence its expression in G1 phase increases in the cell that respond to enter a new cycle after receiving growth factor stimulation [8]. While during $S$ phase the cell automatically suppresses Cyclin D1 formation because it has the ability to inhibit DNA synthesis which may block the cycle progression and lead to the cell-arrest in this position [9]. Over again Cyclin D1 expression elevated during G2 phase which enables the cell to commit to continue the proliferation [10].

Immunohistochemical demonstration of Cyclin D1 have become an important mean for assessing cell proliferation, therefore the immunohistological demonstration of cell cycle related antigens such as CDKs which regulated by the different cyclins could provide a good tool for assessment of cellular proliferation [11].

Flow cytometric technique provides a method for assessing the cells nuclear DNA content and proliferation rate by using the value of S-phase fraction (SPF) [12]. This method has a valuable prognostic role and can predict the treatment response in individual patients [13].

Therefore, this work would assess the prognostic role of the Cyclin D1 expression through immunohistochemical stain by Cyclin D1 protein scoring and quantitative value by image analysis (IOD).

\section{Subjects and Methods}

Tissue samples were obtained from patients diagnosed with breast tumor in the Department of Pathology, Medical Research Institute (MRI), Alexandria University, Egypt, during the period from February to August 2015. Tissue specimens were obtained from 30 cases having IDC and from 10 cases were diagnosed with benign breast lesions in addition to 10 normal breast samples were taken from tissue adjacent to the tumors. Diagnosis of the specimens was made according to the World Health Organization (WHO) classification of the tumors. The malignant cases graded according to Nottingham Prognostic Index (NPI) [14]. All cases were asked to freely volunteer to the study and informed written consents were gathered prior to their inclusion in the study according to the guidance of Scientific Research Ethics Committee (IORG\#: IORG0008812). Samples from all studied cases were subjected to the following:

\section{Pathological parameters}

Age, tumor size, tumor site, LNM, VI and HER2/neu immunopositive stain as well as the immunostaining of ER and PR for the malignant group were obtained from the Pathology Department, MRI.

\section{Histopathological study}

Tissues from all studied cases were fixed in neutral buffered formalin and processed. Paraffin sections, $4 \mu$ thick, were used for routinely staining with H\&E in Histochemistry and Cell Biology Department, MRI to examine the histopathological changes. Stained sections were reviewed by three pathologists.

\section{Flow cytometric analysis}

The homogenized fresh breast tumor samples have been represented for flow cytometric analysis using FACS calibur flow cytometer (Becton Dickinson, Sunnyvale, CA, USA) equipped with a compact air cooked low power 15 mwat argon ion laser beam $(488 \mathrm{~nm})$, data analysis was conducted using DNA analysis program MODFIT (Topsham, USA). This system is used to obtain the percentage of cells in each phase (G0/G1, S and G2/M) of the cell cycle for each sample. These data obtained from Flow cytometry Unit, Mansoura Children Hospital.

\section{Immunohistochemical staining of Cyclin DI}

Immunohistochemical method was utilized to study the expression of Cyclin D1 in paraffin-embedded breast sections [15]. In brief, $5 \mu \mathrm{m}$ thick sections were prepared, deparaffinized using 2 changes of xylene and rehydrated. The sections were submerged in antigen retrieval (citrate buffer saline $\mathrm{pH}$ 8.4) in an oven at $95^{\circ} \mathrm{C}$ for 20 minutes and then left at room temperature for 20 minutes to cool. The sections were treated with $3 \% \mathrm{H}_{2} \mathrm{O}_{2}$ in phosphate buffer saline (PBS), then incubated with serum blocking reagent for 30 minutes. The sections were incubated with primary antibody of Cyclin D1 (Genemed Biotechnologies company, South San Francisco, USA) at $4^{\circ} \mathrm{C}$ overnight. Sections were treated with conjugated secondary antibody (ABC-HRP reagent) for 30 minutes, stained with diaminobenzidine (DAB) and counter stained with haematoxylin. For negative controls, antibody was replaced with PBS. Each step was followed by PBS washing. Evaluation of Cyclin D1-immunohistochemical score was arbitrarily graded as negative, weak, moderate and strong.

\section{Image analysis}

The images of each slide of groups were captured using numerical aperture of a high resolution of 16-bit digital camera (1280X1024 pixels). 
Images were viewed by $40 \mathrm{X}$ objective lens and recorded using Olympus light microscope - equipped with Spot digital camera and computer program MATLAB software (image J) in Histochemistry and Cell Biology Department, MRI.

The integrated optical density (IOD) of Cyclin D1 in normal, benign and IDC groups was analyzed. Maximum, minimum and integrity of intense color based on Gray-level acquisition and analysis of the data level were carried out by reading spot fixed areas of 10 images for each case. The IOD based on Gray-level transition probabilities in digitized images was graded from light to dark (0 up to 250) [16]. The average score across the whole image should be taken; IOD in digitized images was calibrated from strong to light (180 down to 70$)$ by pixel. This calculation was proceed after subtract the pixel value from 250, the pick of lighter elimination.

\section{Statistical Analysis}

Data were normally distributed according to the Kolmogorov-Smirnov (K-S) normality test, and then analyzed using statistical software package SPSS 20. P values $\leq 0.05$ were considered statistically significant.

\section{Results}

\section{Pathological parameters}

All the malignant cases were diagnosed as IDC and graded according to NPI [14]. The grade II (GII) cases were $60 \%$ while grade III (GIII) cases presented
$40 \%$. The routine prognostic parameters revealed that the tumor size ranged between $2-5 \mathrm{~cm}$ in $67 \%$ of GII, $58 \%$ of GIII malignant cases and $70 \%$ of the benign cases. There were $33.3 \%$ of the studied malignant cases with age ranged between $45-55$ years and $60 \%$ of the benign cases ranged in age between $35-45$ years. Moreover, the malignant cases were represented positive vascular invasion expressing in about $93.3 \%$ and $63.3 \%$ of positive lymph node metastasis. According to the immunostaining results of hormonal status noticed $66.7 \%$ of GII and GIII cases expressed positive ER immunostaining. Whereas, PR positive expression was seen in $61.1 \%$ of GII and $66.7 \%$ of GIII cases. Also the prognostic marker of HER2 $\backslash$ neu positive expression resulted in $77.8 \%$ of GII and $75 \%$ of GIII cases.

\section{Histopathological results}

Photomicrographs of paraffin sections were taken under the light microscopy and interpretive by the pathologist. Normal breast tissue showed acini lined by epithelial cells resting on an intact myoepithelial cell layer (Figure 1A). Mild adenosis and cystically dilated ducts were seen in fibrocystic disease of the benign breast case (Figure 1B). The histopathological findings of invasive ductal carcinoma GII revealed neoplastic growth formed of nests and tubules (Figure 1C). Highly pleomorphic vesicular nuclei exhibiting mitotic activity in ductal epithelial cells in GIII as seen in Figure 1D.
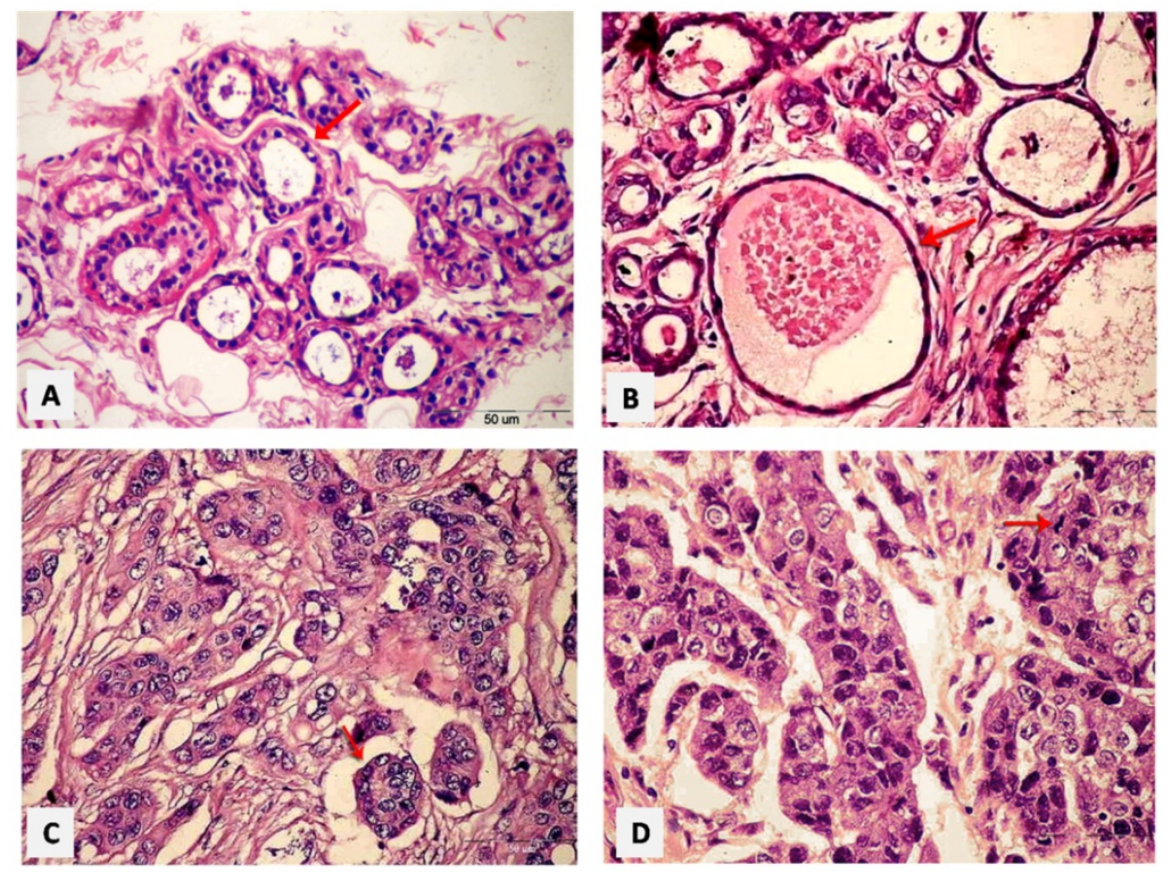

Figure 1. Paraffin sections photomicrographs of breast tissue showing. (A) Normal case: the acini lined by epithelial cells resting on an intact myoepithelial cell layer [arrow], (B) Benign case: a fibrocystic disease case of the breast with mild adenosis as well as cystically dilated ducts [arrow], (C) IDC GIl case: a neoplastic growth formed of nests and tubules [arrow], (D) IDC GIII case: the malignant ductal epithelial cells have highly pleomorphic vesicular nuclei exhibiting mitotic activity [arrow]. [H\&E - Bar $=50 \mu \mathrm{m}$ ]. 


\section{Flow Cytometric Results}

The homogenized specimens of the individual groups have been subjected for flow cytometric analysis for assessing the different phases of the cell cycle. As represented in Table 1.

Table 1. Distribute the percentage of the cell cycle phases by flow cytometry in the individual cases

\begin{tabular}{lllll}
\hline & Normal & Benign & G II & G III \\
\hline Apop. \% & 19.86 & 27.66 & 25.775 & 31.225 \\
G0/1 \% & 54.68 & 47.965 & 57.68 & 44.915 \\
S \% & 11.53 & 2.035 & 16.78 & 9.69 \\
G2/M \% & 1.475 & 0.075 & 1.26 & 9.15 \\
\hline
\end{tabular}

\section{Immunohistochemical results of Cyclin DI}

\section{Immunostaining Positivity Scores}

The immunohistochemical staining appeared as brown staining granules in the nuclei as positive expression of Cyclin D1, while the nuclei having blue color indicated negative reaction. The expression of the Cyclin D1 disappeared in control cases (Figure 2A) and appeared as weak positive brown granules in ductal epithelial cells in benign breast tissue (Figure 2B). Malignant cases of GII revealed strong positive expression of Cyclin D1 in invasive ductal epithelial cells and stroma, while negative stain was seen in the invader cells with vesicular polymorphic nuclei (Figure 2C). A moderate positivity of Cyclin D1 protein expression in trabeculae malignant cells and absent in the vesiculated polymorphic nuclei was seen in GIII (Figure 2D).

Table 2 illustrated the intensities of the immunostaining (negative, week, moderate and strong) and the percentage of positivity-scoring in the studied groups. There was a statistically significant difference $(P=0.007)$ between all the individual groups.

Table 2. Illustration of Cyclin DI-positivity scores in the individual groups

\begin{tabular}{|c|c|c|c|c|c|c|c|c|c|}
\hline \multirow[t]{3}{*}{ Color Intensity } & \multirow{2}{*}{\multicolumn{2}{|c|}{$\begin{array}{l}\text { Normal } \\
\text { Group } \\
(\mathrm{n}=10)\end{array}$}} & \multirow{2}{*}{\multicolumn{2}{|c|}{$\begin{array}{l}\text { Benign Group } \\
(n=10)\end{array}$}} & \multicolumn{4}{|c|}{ Malignant Group } & \multirow[t]{3}{*}{${ }^{\mathrm{MC}} \mathrm{p}$} \\
\hline & & & & & \multicolumn{2}{|c|}{$\begin{array}{l}\text { Grade II } \\
(n=18)\end{array}$} & \multicolumn{2}{|c|}{$\begin{array}{l}\text { Grade III } \\
(n=12)\end{array}$} & \\
\hline & No & $\%$ & No & $\%$ & No & $\%$ & No & $\%$ & \\
\hline Negative & 10 & 100 & 4 & 40.0 & 4 & 22.2 & 2 & 16.6 & \\
\hline Weak & 0 & 00 & 6 & 60.0 & 2 & 11.1 & 1 & 8.3 & $0.007^{*}$ \\
\hline Moderate & 0 & 00 & 0 & 0.0 & 4 & 22.2 & 5 & 41.6 & \\
\hline Strong & 0 & 00 & 0 & 0.0 & 8 & 44.4 & 4 & 33.3 & \\
\hline Total & 10 & 100 & 10 & 100 & 18 & 100 & 12 & 100 & \\
\hline
\end{tabular}

MC: Monte Carlo for Chi square test *: Statistically significant at $\mathrm{p} \leq 0.05$
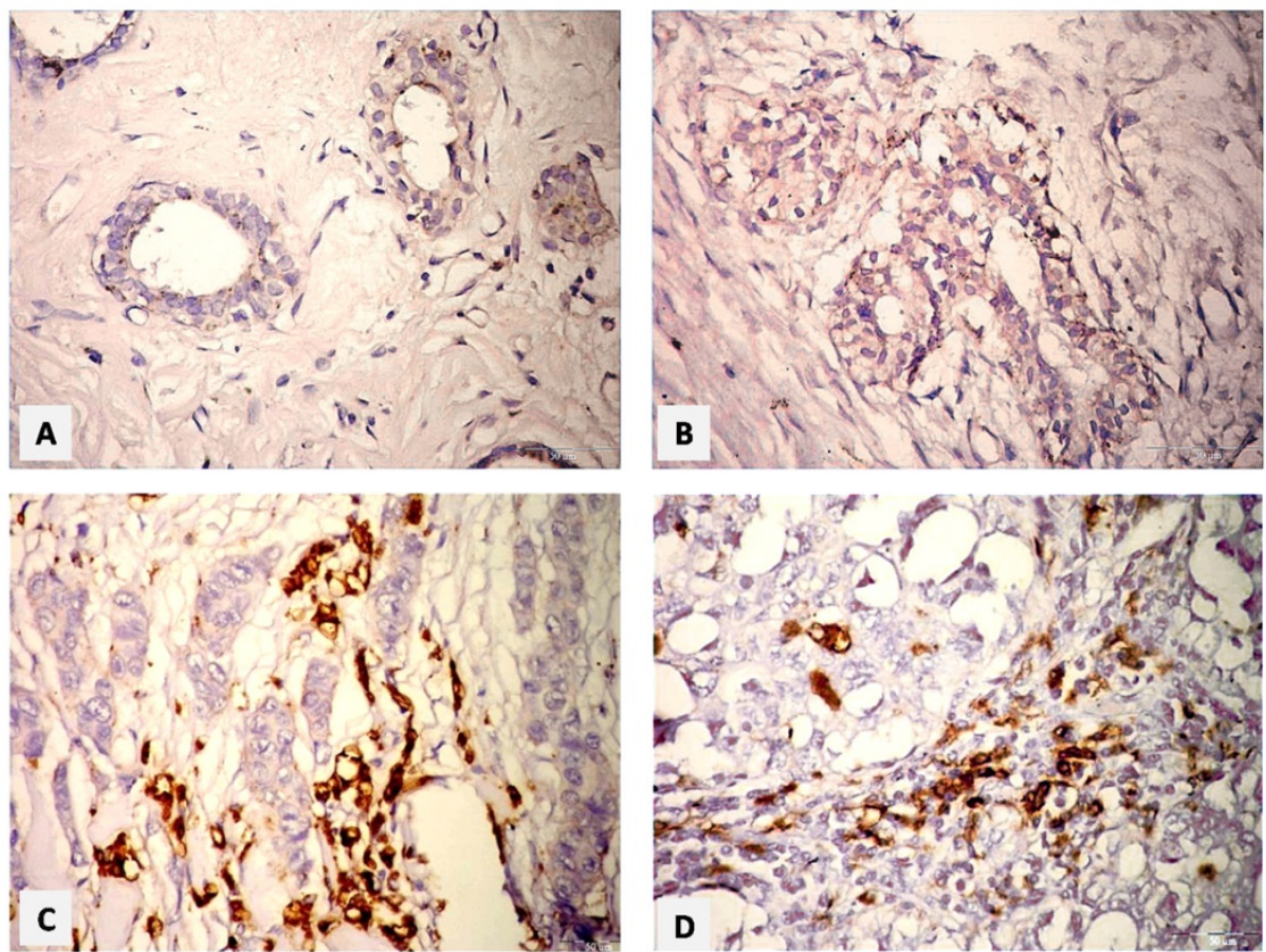

Figure 2. Paraffin sections photomicrographs of breast tissue showing. (A) Normal case: negative Cyclin Dl-immunostaining in the ductal epithelial cells, (B) Benign case: few nuclei with weak expression of Cyclin DI of ductal epithelial cell, and negative one in stromal cells, (C) IDC GII case: a strong positive expression of Cyclin D1 in invasive ductal epithelial cells and stroma, (D) IDC GIII case: moderate positive expression of Cyclin DI in trabeculae malignant cells, and absent in the vesiculated polymorphic nuclei. [ABC\& DAB, Bar= $50 \mu \mathrm{m}]$. 


\section{Association between cyclin DI staining and ER}

Cyclin D1 was statistically significantly correlated with ER-positivity $(\mathrm{P}=0.012)$, hence there was $66.3 \%$ of the all malignant cases were ER-positive compared to $33.3 \%$ were ER-negative. Moreover, the tumors that did not stain for Cyclin D1 were predominantly ER-negative $(83.3 \%)$, adversely to that stained strong-positive for Cyclin D1 were predominantly ER-positive $(91.7 \%)$. As shown in Table 3.

\section{Association between cyclin DI staining and PR}

Cyclin D1 was statistically significantly correlated with PR-positivity $(\mathrm{P}=0.047)$, hence there was $63.3 \%$ of the all malignant cases were PR-positive compared to $36.7 \%$ were PR-negative. As shown in Table 4.

Table 3. Distribute the relationship between Cyclin DI-staining score with ER-positivity

\begin{tabular}{|c|c|c|c|c|c|c|c|c|c|c|c|}
\hline & \multicolumn{8}{|c|}{ Cyclin D1 staining intensity } & \multirow{2}{*}{\multicolumn{2}{|c|}{$\begin{array}{l}\text { Total } \\
(n=30)\end{array}$}} & \multirow[t]{3}{*}{${ }^{\mathrm{MC}} \mathrm{p}$} \\
\hline & \multicolumn{2}{|c|}{$\begin{array}{l}\text { Negative } \\
(\mathrm{n}=6)\end{array}$} & \multicolumn{2}{|c|}{$\begin{array}{l}\text { Weak } \\
(\mathrm{n}=3)\end{array}$} & \multicolumn{2}{|c|}{$\begin{array}{l}\text { Moderate } \\
(\mathrm{n}=9)\end{array}$} & \multicolumn{2}{|c|}{$\begin{array}{l}\text { Strong } \\
(\mathrm{n}=12)\end{array}$} & & & \\
\hline & No & $\%$ & No & $\%$ & No & $\%$ & No & $\%$ & No & $\%$ & \\
\hline \multicolumn{12}{|l|}{ ER } \\
\hline Negative & 5 & 83.3 & 1 & 33.3 & 3 & 33.3 & 1 & 8.3 & 10 & 33.3 & $0.012^{*}$ \\
\hline Positive & 1 & 16.7 & 2 & 66.7 & 6 & 66.7 & 11 & 91.7 & 20 & 66.7 & \\
\hline
\end{tabular}

MC: Monte Carlo for Chi square test *: Statistically significant at $\mathrm{p} \leq 0.05$

Table 4. Distribute the relationship between of Cyclin Dl-immunostaining score with PR-positivity

\begin{tabular}{|c|c|c|c|c|c|c|c|c|c|c|c|}
\hline & \multicolumn{8}{|c|}{ Cyclin D1 staining intensity } & \multirow{2}{*}{\multicolumn{2}{|c|}{$\begin{array}{l}\text { Total } \\
(n=30)\end{array}$}} & \multirow{3}{*}{${ }^{\mathrm{MC}} \mathrm{p}$} \\
\hline & \multicolumn{2}{|c|}{$\begin{array}{l}\text { Negative } \\
(n=6)\end{array}$} & \multicolumn{2}{|c|}{$\begin{array}{l}\text { Weak } \\
(\mathrm{n}=3)\end{array}$} & \multicolumn{2}{|c|}{$\begin{array}{l}\text { Moderate } \\
(n=9)\end{array}$} & \multicolumn{2}{|c|}{$\begin{array}{l}\text { Strong } \\
(n=12)\end{array}$} & & & \\
\hline & No & $\%$ & No & $\%$ & No & $\%$ & No & $\%$ & No & $\%$ & \\
\hline \multicolumn{12}{|l|}{ PR } \\
\hline Negative & 5 & 83.3 & 1 & 33.3 & 3 & 33.3 & 2 & 16.7 & 11 & 36.7 & $0.047^{*}$ \\
\hline Positive & 1 & 16.7 & 2 & 66.7 & 6 & 66.7 & 10 & 83.3 & 19 & 63.3 & \\
\hline
\end{tabular}

MC: Monte Carlo for Chi square test *: Statistically significant at $\mathrm{p} \leq 0.05$

\section{Association between Cyclin D1 staining and S-phase \%}

No significant correlation was observed between Cyclin D1 staining and S-phase \% obtained by flow cytometry as illustrated in Table 5.

\section{Integrated Optical Density (IOD) of Cyclin DI immunostaining}

The IOD mean value for the immunostaining of Cyclin D1 assessed in the individual groups were ranged between (195.54 down to 100.11). There was statistically significant difference between all individual groups compared to the normal group ( $P$ $<0.001)$. And also significant difference was noticed between benign group to the malignant group ( $\mathrm{P}$ $<0.001)$, as well as between GII and GIII $(\mathrm{P}<0.001)$. As shown in Table 6 and Figure 3.

In the correlation between the Cyclin D1 IOD and the different phases of the cell cycle it was noticed that, there was no any statistically association between Cyclin D1 -IOD and G1 phase \% or S phase \% in the all of individual groups. But, there was a decreased statistically association in GIII according to apoptosis \% ( $\mathrm{P}=0.004$ and $\mathrm{r}=-0.757)$, these results are summarized in Table 7 and Figure 4.

Table 5. Correlation between Cyclin D1 immunostaining scores and S-phase \%

\begin{tabular}{|c|c|c|c|c|c|c|c|c|c|c|c|}
\hline & \multicolumn{8}{|c|}{ Cyclin D1 staining intensity } & \multirow{2}{*}{\multicolumn{2}{|c|}{$\begin{array}{l}\text { Total } \\
(\mathrm{n}=30)\end{array}$}} & \multirow[t]{3}{*}{${ }^{\mathrm{MC}} \mathrm{p}$} \\
\hline & \multicolumn{2}{|c|}{$\begin{array}{l}\text { Negative } \\
(\mathrm{n}=6)\end{array}$} & \multicolumn{2}{|c|}{$\begin{array}{l}\text { Weak } \\
(\mathrm{n}=3)\end{array}$} & \multicolumn{2}{|c|}{$\begin{array}{l}\text { Moderate } \\
(\mathrm{n}=9)\end{array}$} & \multicolumn{2}{|c|}{$\begin{array}{l}\text { Strong } \\
(\mathrm{n}=12)\end{array}$} & & & \\
\hline & No & $\%$ & No & $\%$ & No & $\%$ & No & $\%$ & No & $\%$ & \\
\hline \multicolumn{12}{|l|}{ S-Phase } \\
\hline Low $(\leq 10 \%)$ & 2 & 33.3 & 0 & 00 & 4 & 44.4 & 3 & 25.0 & 9 & 30.0 & 0.657 \\
\hline High $(>10 \%)$ & 4 & 66.7 & 3 & 100 & 5 & 55.6 & 9 & 75.0 & 21 & 70.0 & \\
\hline
\end{tabular}

MC: Monte Carlo for Chi square test

Table 6. Distribution of the IOD Cyclin DI immunostaining in individual groups

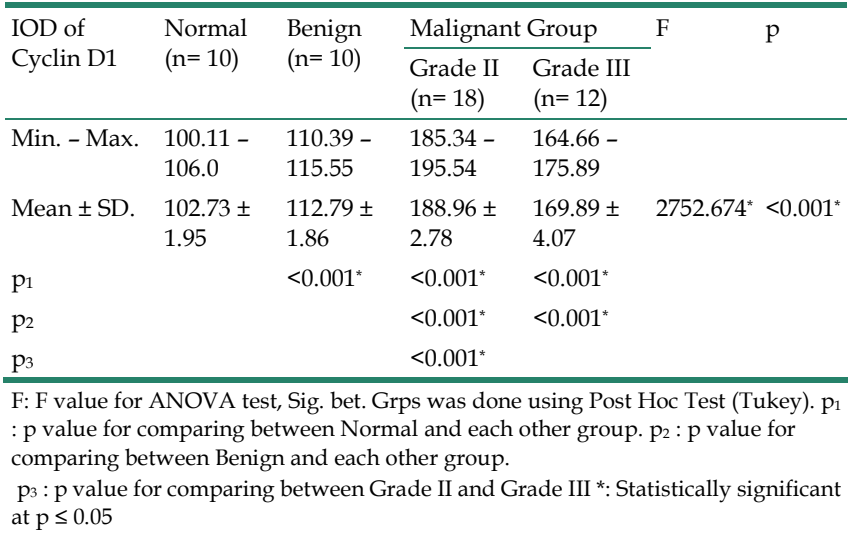

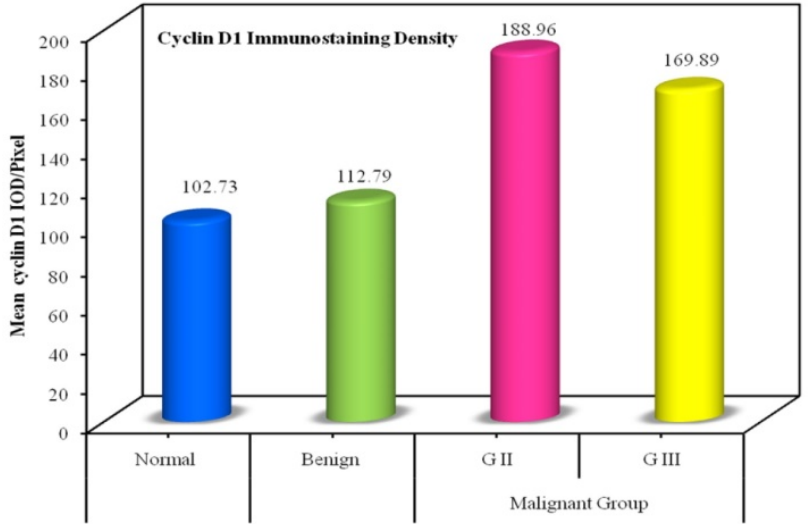

Figure 3. Bar chart represents the mean Cyclin DI IOD /pixel in the individual groups. 
Table 7. Correlation between Cyclin DI IOD with the different phases of the cell cycle

\begin{tabular}{|c|c|c|c|c|c|}
\hline & & \multirow{2}{*}{$\begin{array}{l}\text { Normal } \\
(n=10)\end{array}$} & \multirow{2}{*}{$\begin{array}{l}\text { Benign } \\
(n=10)\end{array}$} & \multicolumn{2}{|c|}{ Malignant } \\
\hline & & & & $\begin{array}{l}\text { Grade II } \\
(n=18)\end{array}$ & $\begin{array}{l}\text { Grade III } \\
(n=12)\end{array}$ \\
\hline \multirow[t]{2}{*}{ Apop. \% } & $\mathrm{r}$ & -0.097 & -0.300 & 0.143 & $-0.757^{*}$ \\
\hline & $\mathrm{p}$ & 0.790 & 0.400 & 0.572 & 0.004 \\
\hline \multirow[t]{2}{*}{ G0/1 \% } & $\mathrm{r}$ & -0.218 & -0.593 & -0.095 & 0.078 \\
\hline & $\mathrm{p}$ & 0.546 & 0.071 & 0.707 & 0.809 \\
\hline \multirow[t]{2}{*}{ S \% } & $\mathrm{r}$ & -0.138 & 0.239 & -0.195 & 0.457 \\
\hline & $\mathrm{p}$ & 0.703 & 0.507 & 0.439 & 0.135 \\
\hline \multirow[t]{2}{*}{ G2/M \% } & $\mathrm{r}$ & -0.073 & 0.287 & 0.170 & -0.071 \\
\hline & $\mathrm{p}$ & 0.840 & 0.421 & 0.500 & 0.827 \\
\hline
\end{tabular}

$r$ : Pearson coefficient *: Statistically significant at $p \leq 0.05$.

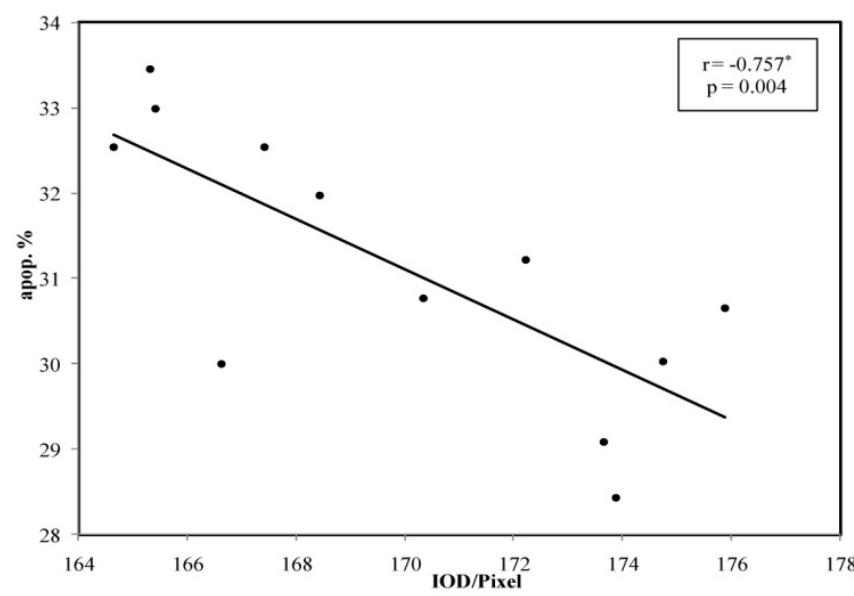

Figure 4. Lin chart illustrates the correlation between Cyclin D1 IOD in Grade III with percentage of apoptotic phase. Note: the significant correlation $\mathrm{p}<0.004$.

\section{Discussion}

The morphological assessment of the differentiation degree in breast cancer has been provided useful prognostic information and the histological grade forms part of the multifactor Nottingham prognostic index together with tumor size and lymph node stage, which is used to assure individual patient for proper therapy [17].

The present results of breast cancer showed that the age of major cases was ranged between $>35$ to 55 years and the tumor size was $>2$ to $5 \mathrm{~cm}$ in all studied malignant cases. These results are consistent with previous study reported that IDC is the most common histological type of invasive breast cancer [18]. In accordance, EL-Fiky et al., 2015 [19] reported that 98\% of the breast cancer cases were IDC with the age ranged from $>35$ to 55 years and the tumor size from $>2$ to $5 \mathrm{~cm}$ were seen in $73 \%$ of malignant cases. The present result revealed that $60 \%$ of studied cases were GII and $40 \%$ were GIII of IDC. It was noticed that the most common histological type of breast cancer was invasive ductal carcinoma in our country. This result is supported by previous studies who reported that most of the breast cancer cases undergoing surgical resection are GII and GIII of IDC [20, 21].

In addition, the present immunohistochemical studies for hormone status represented that the total positive malignant cases were ER and PR with percentage of $66 \%$ and $63 \%$ respectively, in addition to HER2/neu were positive in $76 \%$. Whereas the previous study reported that the percentage of ER and PR positive were $59 \%$ and $57 \%$, while $38 \%$ were HER2/neu positive [19]. So, the present results attributed the increment of the immunohistochemical parameters incidence may be related to the environmental cofactors due to changes in reproductive factors and lifestyle in our country.

As regard to cyclin $\mathrm{Dl}$ expression, the present result showed that it was mostly nuclear staining with variable range of stain intensity between different sections in the individual groups. Some cases with strong nuclear staining, the cytoplasm was also stained. This result was agreed with several previous studies who stated that, Cyclin D1 showed nuclear and cytoplasmic staining and had an extensive range of intensities between different sections [22, 23]. Furthermore, there was a negative expression for Cyclin D1 protein in normal ductal epithelial cells, while the benign group revealed week positivity immunostaining Cyclin D1 in $60 \%$, whereas, the malignant group represented a variable positivity of immunostaining scores; they were classified as 3 $(10 \%)$ cases were weak, $9(30 \%)$ moderate cases and 12 (40\%) strong expression cases. The remaining 6 cases $(20 \%)$ did not show any considerable staining for Cyclin D1 in the nucleus and were classed as negative nuclear stain. These findings for scoring expression were agreed with Gillet et al., 1996 [24], who stated in their study that, moderate /strong staining of Cyclin D1 had a longer relapse-free survival than patients whose tumors stained weakly or negatively for Cyclin $\mathrm{D} 1$ with a great significant difference $(\mathrm{P}=0.007)$. For a good willing, the present study represented the major of malignant cases had expressed moderate /strong staining of Cyclin D1 in 70\% of studied cases. Other demonstration found that Cyclin D1 staining could provide significant prognostic information, under the experimental study modulation of MCF-7 cell line growth rate by regulated overexpression or suppression of endogenous Cyclin D1 or CDK4 levels. $\mathrm{SO}$, they had suggested the inhibition of cyclin $\mathrm{Dl} / \mathrm{CDK} 4$ activity might be important in considering drugs of future therapies [25], also, they reported that Cyclin D1 was considered as a significant prognostic marker. 
On the other hand, the present study declared that Cyclin D1 was statistically significant correlated with ER-positivity $(\mathrm{P}=0.012)$, hence Cyclin D1-staining in all malignant cases scored $66.7 \%$ ER-positive versus to 33.3 \% ER-negative. Moreover, Cyclin D1 was statistically significant correlated with PR-positivity $(\mathrm{P}=0.047)$, hence there was $63.3 \%$ of all malignant cases were PR-positive compared to $36.7 \%$ were PR-negative. So, the result may be suggested that the over-expression of Cyclin D1 is a good predictive factor in invasive breast cancer. Our suggestion was supported by the previous study, who stated that patients with higher Cyclin D1 expression had longer both overall survival and relapse-free survival [26]. In addition, the present results for the associated correlation with hormonal status of ER and PR found significant correlation between Cyclin D1 protein expression and the positivity of ER and PR were in agreement with additional studies which reported that high Cyclin D1 expression correlated strongly with ER and PR levels in breast cancer indicated that the significant correlation between Cyclin D1 and the positivity of ER and PR had a good prognosis $[15,27]$.

For confirming our study results, the correlation between Cyclin D1-staining scores and the percentage of S-phase obtained by flow cytometry which showed no significant correlation between Cyclin D1 protein and increased S-phase \%. These finding were exactly in accordance with Gillet et al., 1996 [24], who stated that, Cyclin D1 staining did not appear to correlate with an increased S-phase fraction as judged by flow cytometry. This contradictory behavior explained that Cyclin D1 acts as a negative regulative protein under some conditions rather than a positive regulator in the cell cycle, i.e. the modest increase in Cyclin D1 expression could hasten the G1 phase while the overexpression may lead to block the progression through the S-phase [28, 29].

Moreover, the Cyclin D1-immunostaining density (IOD) in the present study showed that, there was statistically significant difference between all individual groups compared to the normal group ( $\mathrm{P}$ $<0.001)$. Also significant difference was noticed between benign group and malignant group ( $\mathrm{P}$ $<0.001$ ), as well as between GII and GIII ( $\mathrm{P}<0.001$ ). These findings were in agreement with a previous study who stated that the image cytometry showed a high significant difference $(\mathrm{P}<0.005)$ in malignant group compared to benign individual cases and a high significant difference $(\mathrm{P}<0.001)$ between the GII and GIII of the malignant group studies. So, those results could be revealed that the digital data IOD for Cyclin D1 measurement have identified a potentially valuable evidence role of proliferative fraction in breast carcinomas [30]. Hence, it may by suggested that the immunostaining evaluation using image analysis for counting for density of stain (IOD), reflected the role of the image analysis as a valuable method for assessing tumor cell proliferation. In harmony to the present suggestion, the scoring and image cytometry evaluation using immunohistochemistry of Cyclin D1 protein marker stated that the variations of protein expression in tissue sections could yield prognostic information or could be useful in determining subtle effects of curative or prevention therapies [31]. Therefore, Cyclin D1 protein may be used parallel with ER \& PR as valuable prognostic markers in invasive breast cancer and can be targeted in the future therapeutic approaches. Further studies of the Cyclin D1 protein on different cancer tissues are recommended.

\section{Acknowledgments}

Prof. Dr. Mona Samy, at Flow cytometry Unit Mansoura Children Hospital, has given help and valuable information regarding application of flow cytometer analysis.

\section{Competing Interests}

The authors have declared that no competing interest exists.

\section{References}

1. Ferlay J, Soerjomataram I, Dikshit R, Eser S, Mathers C, Rebelo M, et al. Cancer incidence and mortality worldwide: sources, methods and major patterns in GLOBOCAN 2012. Int J Cancer. 2015; 136: E359-86.

2. Howlader N, Noone AM, Krapcho M, Garshell J, Neyman N, Altekruse SF, et al. SEER Cancer Statistics Review, 1975-2012, based on Nov 2014 SEER data submission. Bethesda, MD: National Cancer Institute; 2015.

3. Biomedical informatics and medical statistics. Alex Cancer Registry. MRI. Alex U; 2015.

4. Lodish H, Berk A, Zipursky SL, Matsudaira P, Baltimore D, Darnell J. Molecular Cell Biology, 4th ed. New York: Freeman; 2000: 222-46.

5. Duronio RJ, Xiong Y. Signaling Pathways that control cell proliferation. Cold Spring Harb Perspect Biol. 2013; doi:10.1101/cshperspect.a008904.

6. Rhind N, Russell P. Signaling pathways that regulate cell division. Cold Spring Harb Perspect Biol 2012; doi: 10.1101/cshperspect.a005942.

7. Sjostrom J, Makela T. Apoptosis and the cell cycle in human disease. Encyclopedia of Life Sci. 2006; doi: 10.1002/9780470015902.a0006043.

8. Hitomi M, Stacey DW: Cyclin D1 production in cycling cells depends on ras in a cell-cycle-specific manner. Curr Biol. 1999; 9: 1075-84.

9. Fukami-Kobayashi J, Mitsui Y: Cyclin D1 inhibits cell proliferation through binding to PCNA and CDK2. Experimental Cell Research. 1999; 246: 338-47.

10. Yang K, Hitomi M, Stacey DW. Variations in Cyclin D1 levels through the cell cycle determine the proliferative fate of a cell. Cell Div. 2006; doi: 10.1186/1747-1028-1-32.

11. Zaha DC. Significance of immunohistochemistry in breast cancer. World J Clin Oncol. 2014; 5: 382-92.

12. Margolese RG, Hortobagyi GN, Buchholz TA. Natural history and prognostic markers. In: Kufe DW, Pollock RE, Weichselbaum RR, Bast RC, Gansler TS, Holland JF, et al. eds. Holland-Frei Cancer Medicine, 6th ed. Hamilton: BC Decker Inc; 2003: 156-77.

13. Duigou F, Herlin P, Marnay J, Michels JJ. Variation of flow cytometric DNA measurement in 1,485 primary breast carcinomas according to guidelines for DNA histogram interpretation. Cytometry. 2000; 42: 35-4.

14. D'Eredita G, Giardina C, Martellotta M, Natale T, Ferrarese F. Prognostic factors in breast cancer: the predictive value of the Nottingham Prognostic Index in patients with a long-term follow-up that were treated in a single institution. Eur J Cancer 2001; 37: 591-6. 
15. Peurala E, Koivunen P, Maria HK, Bloigu R, Vuorinen AJ. The prognostic significance and value of Cyclin D1, CDK4 and p16 in human breast cancer. Breast Cancer Research. 2013, doi:10.1186/bcr3376.

16. Matos LL, Stabenow E, Tavares MR, Ferraz AR, Capelozzi VL, Pinhal MA. Immunohistochemistry quantification by a digital computer-assisted method compared to semiquantitative analysis. Clinics. 2006; 61: 417-24.

17. Zhao X, Malhotra GK, Lele SM, Lele MS, West WW, Eudy JD, et al. Telomerase-immortalized human mammary stem/progenitor cells with ability to self-renew and differentiate. Proc Natl Acad Sci. 2010; 107: 14146-51.

18. Shi WB, Yang LJ, Hu X, Zhou J, Zhang Q, Shao ZM. Clinicopathological features and prognosis of invasive micropapillary carcinoma compared to invasive ductal carcinoma: a population-based study from China. PLoS One. 2014; doi: 10.1371/journal.pone.0101390.

19. EL-Fiky SH, Yahia MA, AL Sedfy AS, AL-Qadasi SA. Immunohistochemical expression of Fn14 in invasive ductal carcinoma (IDC) and its correlation with clinical and histopathological parameters of human breast cancer. Int Res J Medical Sci. 2015; 3: 7-15.

20. Hüsemann Y, Geigl JB, Schubert F, Musiani P, Meyer M, Burghart E, et al. Systemic spread is an early step in breast cancer. Cancer Cell. 2008; 13: 58-68.

21. Sofi GN, Sofi JN, Nadeem R, Shiekh RY, Khan FA, Sofi AA, et al. Estrogen receptor and progesterone receptor status in breast cancer in relation to age, histological grade, size of lesion and lymph node involvement. Asian Pac J Cancer Prev. 2012; 13: 5047-52.

22. Bartkova J, Lukas J, Strauss M, Bartek J. Cyclin D1 oncoprotein aberrantly accumulates in malignancies of diverse histogenesis. Oncogene. 1995; 10: 775-78.

23. Gillett C, Fanti V, Fisher C, Bartek J, Dickson C, Barnes D, et al. Amplification and overexpression of Cyclin D1 in breast cancer detected by immunohistochemical staining. Cancer Res. 1994; 54: 1812-17.

24. Gillett C, Smith P, Gregory W, Richards M, Millis R, Peters G, et al. Cyclin D1 and prognosis in human breast cancer. Int J Cancer. 1996; 69: 92-9.

25. Grillo M, Bott MJ, Khandke N, McGinnis JP, Miranda M, Meyyappan M, et al. Validation of Cyclin D1/CDK4 as an anticancer drug target in MCF-7 breast cancer cells: Effect of regulated overexpression of Cyclin D1 and siRNA-mediated inhibition of endogenous Cyclin D1 and CDK4 expression. Breast Cancer Res Treat. 2006; 95: 185-94.

26. Bilalović $\mathrm{N}$, Vranić $\mathrm{S}$, Basić $\mathrm{H}$, Tatarević A, Selak I. Immunohistochemical evaluation of Cyclin D1 in breast cancer. Croat Med J. 2005; 46: 382-8.

27. Roy PG, Thompson AM. Cyclin D1 and breast cancer. Breast. 2006; 15: 718-27.

28. Bates S, Peters G. Cyclin D1 as a cellular proto-oncogene. Sem Cancer Biol. 1994; 6: 73-82.

29. Draetta G. Mammalian G1 cyclins. Cur Opin Cell Biol. 1994; 6: 842-46.

30. Tobin NP, Lundgren KL, Conway C, Anagnostaki L, Costello S. Automated image analysis of Cyclin D1 protein expression in invasive lobular breast carcinoma provides independent prognostic information. Hum Pathol. 2012; 43: 2053-61.

31. Liu SC, Zhang SY, Babb JS, Ridge JA, Klein-Szanto AJ. Image cytometry of Cyclin D1: a prognostic marker for head and neck squamous cell carcinomas. Cancer Epidemiol Biomarkers Prev. 2001; 10: 455-9. 